\title{
sciendo

\section{Towards Efficient Waste Management in Latvia: An Empirical Assessment of Waste Composition}

\author{
Anna KUBULE ${ }^{1 *}$, Kaspars KLAVENIEKS ${ }^{2}$, Rudite VESERE $^{3}$, Dagnija BLUMBERGA $^{4}$ \\ ${ }^{1-4}$ Institute of Energy Systems and Environment, Riga Technical University, \\ Azenes iela 12/1, Riga, LV-1048, Latvia
}

\begin{abstract}
Waste management system is a complex system involving numerous waste streams, collection schemes, treatment processes and various actors. Bus as well as many other systems, waste management is recently experiencing new and more sustainable development trends including the promotion of circular economy and increased material recycling. Hence there is a need for the implementation of an improved waste management system that requires a significant and thorough planning stage, the results of which will significantly depend on the availability of detailed information of the possible waste flows and waste composition. The aim of this paper is to experimentally determine and analyse the composition of unsorted municipal waste to provide assessment for incorporating waste composition analysis into further planning and modelling of a next generation waste management system in Latvia. The experimental results indicate that the unsorted municipal waste stream comprises of up to $32.9 \%$ of recyclable materials and $29.2 \%$ of biodegradable wastes. Thus almost $60 \%$ of the waste currently being subjected to unsorted waste management system in Latvia could potentially be source separated ensuring higher quality of the recovered materials and promoting circular value chains. The results indicate a slight difference between waste composition in different waste management regions, thus noting that, in addition to the number of inhabitants and their habits, the local system in each waste management region may influence the composition of the collected wastes.
\end{abstract}

Keywords - Circular economy; multiple regression analysis; waste composition analysis; waste management system

\section{INTRODUCTION}

Our overall consumption is continuously growing, as well as the amounts of produced waste, but the one thing that is constant is the Earth's finite resources. To find a long term solution for these challenges, we have to consider our waste management systems as a source for valued resources or resource banks [1], e.g. reuse and recycle wastes, recover energy [1] or even upgrade waste into valuable products [1]. However, current waste management systems are focused only on waste treatment, and lack considerations of the potential waste valorisation opportunities [1].

The concept of the circular economy is assumed to hold the solution or at least a remedy for such complex global challenges, including decoupling of resource use and economic growth, resource scarcity, climate change, increased waste generation etc. [1]. Circular economy aims to overcome the linear production approach that is based on the take-make-consume and dispose trend and to transform the economy to a circular operating pattern that is improving resource and energy efficiency, and involving resource recovery and reuse [1]. However, a significant gap exists between circular economy practical solutions and actual motivation of individual local actors to

\footnotetext{
* Corresponding author.

E-mail address: anna.kubule@rtu.lv
} 
implement those solutions [1]. Cobo et al. [1] propose the design of efficient and circular integrated waste management systems (CIWMS) as a significant tool for the transition towards a circular economy.

Though with 1.26 tons of non-hazardous waste (including household and industrial waste) per inhabitant in 2016, Latvia is one of EU 28 countries with the least amount of waste produced per capita [1], the national tendency shows a significant increase of generated waste amount from 362 $\mathrm{kg}$ per capita in 2002, to $1098 \mathrm{~kg}$ per capita in 2017 [1]. As well, there is a significant linear correlation between per capita generated waste and per capita GDP $\left(r^{2}=0.78\right)$, indicating that further economic growth will only lead to the increase of per capita waste generation, if no meaningful decoupling measures are undertaken. A recent analysis of the performance of national municipal waste treatment systems in EU27 countries places Latvia together with the lowest performing countries because waste is mainly landfilled instead of used for recycling, composting and energy recovery [1]. But actually, the situation in Latvia is quite better as $71.6 \%$ of the treated waste in 2016 was recycled and only $20.5 \%$ landfilled [1].

One of the main waste policy planning documents in Latvia is the National waste management plan 2013-2020 [1], thus the development of next plan for the planning period which will start after 2020 should be drafted soon. In previous planning periods, Latvia has mainly focused on implementing the EU requirements for waste management [1]. But in order to promote sustainable development of Latvia's waste management system, the next National waste management plan should incorporate more in-depth sustainability and circularity approach as well as thorough analysis and evaluation of the existing system.

The waste management system is a complex system involving numerous waste streams, collection schemes and treatment processes; all these stages should be considered for the development of an integrated waste management system [1]. Cobo et al. [1] stress the importance of preparatory analysis of alternatives prior to the design stage for an improved waste management system. The data on the actual waste flows is the principal input for the waste management system analysis [1]. The analysis of Bisinella et al. [1] indicates that waste composition data are highly important for potential resource recycling and transition towards a circular economy, as well as it has significant impact on Life cycle assessment of waste management alternatives. Similarly, Arena and Di Gregorio [1] underline that waste management planning and decision making is a complex issue that may involve both accurate and inaccurate or missing data. Keser et al. [1] note that applying locally significant variables can lead to better planning of waste management. Overall, the implementation of an improved waste management system requires significant and thorough planning stage, the results of which will significantly depend on the availability of detailed information of the possible waste flows and waste composition. Hence, in order to assess the existing waste management system and to plan its further development, data that characterizes household waste volumes, waste composition, the behaviour of waste producers and its trends is required. The availability of such data allows allocating adequate capacities for waste collection, transportation, treatment and disposal [1].

Moreover, the application of modelling methods for the analysis of waste volume and composition data allows estimating a prediction for future development of the existing waste management system and its long-term planning, as well as provides input for further scientific studies regarding measures for decoupling of waste generation and economic growth, i.e. promotion of a circular economy. The use of waste capacity prediction models is widespread and numerous methods have been applied, e.g., trend analysis, various regression techniques, multiple linear regression and others [1]. Various authors have identified different explanatory factors for municipal waste generation. For a case of Turkish provinces Keser et al. [1] name unemployment rate, temperature, higher education graduate's ratio and agricultural production value. Oribe- 
Garcia et al. [1] identify urban morphology, tourism activity, educational level, economic dynamism and resources of population as influential factors for Biscay municipalities. Kolekar et al. [1] name food habits, standard of living, degree of commercial activities and seasons as important factors that influence the composition of municipal solid waste (MSW). Mohammadi et al. [1] use waste composition data as one input for a mixed integer linear programming model for optimal planning of waste management supply chain network. However, modelling may be limited by the availability of household waste composition data, e.g., Lebersorger and Schneider [1] report lack of systematic and comparable data regarding household food waste composition.

In Latvia, the accounts of the amount of waste managed by the waste management system are kept by the national waste statistical database [1]. This database provides information on various waste management activities, such as waste generation, collection, recycling, recovery, disposal. The database also provides information on various waste streams both by origin and by type, such as collected paper packaging, recycled metal, unsorted municipal waste, etc. However, the statistics do not provide details on composition of the unsorted municipal waste stream. The unsorted municipal waste stream constitutes a significant part of the total generated municipal waste ( $67 \%$ in 2017 , or 571 thousand tonnes) [1], and includes a wide range of materials biodegradable waste, recyclable materials, domestic hazardous waste, etc. Therefore, a comprehensive study on unsorted municipal waste composition is necessary in order to plan the development of the waste management system, increase the amount of waste recovery and reduce the amount of landfilled waste (sanitary landfill). Such composition analysis will ensure more efficient planning of waste collection (including separate collection system), forecast of the necessary recycling and recovery capacity and the development policy, as well as evaluation of the efficiency of existing technological solutions and applied policy instruments. Thus, the aim of this paper is to experimentally determine and analyse the composition of unsorted municipal waste to provide assessment for incorporating waste composition analysis into further planning and modelling of a next generation waste management system in Latvia.

\section{MATERIALS AND METHODS}

The objective of the research was to obtain detailed information on the composition of the unsorted municipal waste in Latvian cities, to ensure wide geographical coverage and to enable the collected data to be further used for evaluation of aspects that have an impact on unsorted municipal waste composition. The analysis of the applicable experimental methods for determination of the composition of the unsorted municipal waste stream indicated two main types of approaches:

1. Physical sorting of waste - sorting at waste collection sites (direct sorting of waste containers) or sorting at waste pre-treatment centres (centralised facilities located within or outside the landfills) i.e. waste collected in one collection trip;

2. Determination of composition based on material flow analysis (MFA) according to material life cycle assessment approach.

MFA includes systematic analysis of material and element flows and stocks within a certain system limited by space and time [1]. Thus, MFA can identify and link the sources and destinations of each considered material; however, this requires access to very detailed data. However, Bisinella et al. [1] note that few LCAs actually consider the effects of waste composition. Considering the available data sources and the objective of the study, the MFA based methods could not be applied in the present research - the limitations are mainly related to the lack of citylevel precise data that characterize resource and raw material consumption for the production of goods, consumer habits and lifespan of goods before they become waste. Therefore, physical sorting of waste is selected for this study. 
Dahlen and Lagerkvist [1] reviewed 20 physical sorting methods commonly used in Europe and internationally for solid waste component analysis. On the other hand, various researchers note that, as there are no commonly agreed standard methods for household waste consumption analysis and due to the methodological differences between the available methods, most previous studies are not comparable [1].

Commonly used physical sorting methods in European Union Member States that are also considered for the current study include "Nordtest" NT ENVIR 001 [26]; Development of a methodological tool to enhance the precision \& comparability of solid waste analysis data (SWAtool) [29] and CEN Standards and Technical Recommendations [30]. These methods are largely similar and their variations are determined by the breakdown and definitions of the waste to be sorted out, the sorting process, sample distribution by waste producer groups and subgroups to be included in the research.

The "SWA-tool" methodology [29] was originally developed on behalf of the European Commission (EC) with an aim to develop an EU level waste composition analysis standard. The method is designed to determine the composition and volume of generated household waste, as well as waste that originated in companies, institutions or industrial plants, but its composition may be assumed similar to household waste. The scientific research on EC's "SWA-tool" has pointed out that the method's disadvantages are its high costs as the method involves sorting each individual waste container. It has been recommended for studies aimed at comparing the composition of waste generated at individual households. Since the objective of the current study is broader and its target group is not focused solely on separate households and their comparison, this method was not selected.

The international CEN/TR/LVS Standards and Technical Recommendations [26] are applicable to regulated areas where waste composition assessment has to be carried out by accredited/regulated methods and/or to carry out the accreditation process of the inspection body. The use of CEN/TR/LVS standards and technical recommendations is optimal in cases where a detailed determination of the composition of the waste is necessary, including not only the analysis of waste stream composition, but also the characterization of its physicochemical properties. For example, when analysing the operation of waste recovery facilities, a precise description of the incoming waste stream, the produced secondary raw material or the final product of the treatment or recovery process is needed. However, for the current study this method is not optimal, because its use is associated with a much larger amount of time and financial resources, which in turn would reduce the total population to be included in the study, thus reducing the representativeness of the obtained data and would not ensure the achievement of the objective of this study.

The NT ENVIR 001 [26] method is designed to provide a uniform approach to waste composition analysis, and is mainly aimed at Northern European countries. But as the method allows for adjustments to the waste groups and sources of waste being analysed, its application is very widespread - from a general study of waste composition and amount of generated waste, to a case study to assess the performance of a waste sorting station or recycling facility. The NT ENVIR 001 method is the most appropriate for the current study compared to the other considered methods. The main advantage of the method is the possibility to sample according to waste collection routes, which firstly guarantees that large number of households are included in the sample, secondly, the processing and sorting of the sample can be carried out in the location of the waste management infrastructure, where the necessary equipment is available; no administrative constraints are foreseen, as would be the case for sorting separate waste containers at waste generation sites. When analysing the possibilities to apply this method in Latvia, it was concluded that there are no restrictions on either methodological or material technical solutions; 
as a result, the method can be recognized as conforming to the conditions of Latvia and the particular research.

As the aim of the study was to obtain comprehensive and detailed information on the unsorted municipal waste flow in Latvia, the methodology used in the study is based on the principles and recommendations of NT ENVIR 001 and adapted to the purpose of the study, specific Latvian conditions, the planned work volume and other limiting factors.

\subsection{Geographic Coverage}

To obtain the most comprehensive data regarding unsorted municipal waste flows in the country, 32 cities in different regions of Latvia were selected for the study based on population and administrative division of territories (Table 1). Selected cities were grouped by population and by the administrative rank: national cities and regional cities (the administrative division of Latvia distinguishes nine national cities and 67 regional cities). The aim of the applied selection of the cities was to achieve the widest possible geographical coverage, thus ensuring the evaluation of the whole national waste management system, and to provide an opportunity to assess the interrelationships between waste composition and socio-economic factors in different areas.

\section{TABLE 1. GeOgRAPHICAL COVERAGE OF THE RESEARCH}

\begin{tabular}{lll}
\hline Number of inhabitants & Regional cities & National cities \\
\hline Less than 1000 & Durbe, Subate, Ainazi, Piltene, Varkava & \\
$1000-5000$ & $\begin{array}{l}\text { Aloja, Broceni, Ergli, Jaunjelgava, } \\
\text { Ligatne, Valka, Vilani }\end{array}$ & \\
$5000-10000$ & $\begin{array}{l}\text { Bauska, Dobele, Gulbene, Kraslava, } \\
\text { Ludza, Madona, Smiltene, Talsi }\end{array}$ & \\
$10000-40000$ & Kuldiga, Ogre, Tukums & $\begin{array}{l}\text { Jekabpils, Rezekne, Valmiera } \\
\text { Daugavpils, Jelgava, Jurmala, } \\
\text { More than } 40000\end{array}$ \\
\hline
\end{tabular}

\subsection{Sampling}

As the aim of the study was to determine the composition of unsorted municipal waste, it was necessary to ensure that the collected samples originate in households or, in case they were generated in companies or other institutions - that their amount and composition correspond to municipal solid waste produced by households. The sampling is performed in the previously defined 32 target cities thus ensuring that the samples represent the waste of the designated geographical and administrative area. One of the initial challenges for sampling planning was to select certain already existing waste collection routes that would ensure sufficient number of households in the sample, e.g., by servicing mainly apartment buildings and single-family homes. In order to avoid undesirable admixtures of inappropriate waste into the test sample, the compliance of the selected waste collection route to particular selection criteria was determined in consultation with each waste management company as they have first-hand knowledge regarding the waste producers served on each particular route. The main principles for the selection of waste collection routes were as follows: (1) municipal waste is collected only from a particular city, without servicing rural areas, (2) only unsorted municipal waste is collected on the route (however up to $10-15 \%$ by volume addition of unsorted municipal waste from companies and institutions was allowed, but no industrial waste or other specific waste may be 
collected on the route, including agricultural waste, graveyard waste, etc.). In order to avoid waste fluctuations on a weekly basis, waste collection routes were selected, as far as possible, with a regular collection frequency of one time per week. Although, in the optimal case, the waste composition tests should be carried out four times a year, thus avoiding the effect of seasonality, this principle was not observed due to resource limitations in the study and the collection and sorting of samples was carried out during the autumn and winter months, from November 2016 to March 2017. In each city, five samples were collected and analysed during this period - one sample per month. The samples were taken from the waste delivered at the waste management facilities (transhipment - sorting stations and sanitary waste landfills). After discharging of each truck, the samples were taken with a front loader and the prepared test sample weighed at least $250 \mathrm{~kg}$.

\subsection{Sorted out Fractions}

The classification of waste fractions to be sorted out (Table 2) was determined according to NT ENVIR 001 methodology [26] and the standard LVS EN 15440: 2011 "Solid recovered fuels Methods for the determination of biomass content" [26]. This standard is widely applied, so the classification of waste fractions is widely known and understandable.

\section{TABLE 2. ClassifiCATION OF EXPERIMENTALly IDENTIFIED WASTE COMPONENTS}

\begin{tabular}{|c|c|c|c|}
\hline \multicolumn{2}{|c|}{ No. Waste fraction } & \multicolumn{2}{|c|}{ No. Waste fraction } \\
\hline 1 & $\begin{array}{l}\text { Biodegradable waste (garden and park waste } \\
\text { (plant leaves, grass), food waste) }\end{array}$ & 15 & Soft Plastic (Packaging Bags) \\
\hline 2 & Paper, cardboard (waste paper) & 16 & Dense Plastic (Household Items) \\
\hline 3 & Paper, cardboard (packaging) & 17 & Dense Plastic (Packaging) \\
\hline 4 & Beverage packaging (tetra packs) & 18 & Carpets (rugs, blankets) \\
\hline 5 & Wood & 19 & Iron (household articles of iron) \\
\hline 6 & Wood (packaging) & 20 & Iron (Packaging) \\
\hline 7 & Hygienic waste (napkins, diapers, etc.) & 21 & Non-ferrous metal (non-ferrous household items) \\
\hline 8 & Textiles (clothing, other fabric products) & 22 & Non-ferrous metal (Packaging) \\
\hline 9 & Leather, rubber & 23 & Packaging for composite materials (chips, coffee packs) \\
\hline 10 & Glass (tableware, household items, fragments) & 24 & Fine matter (fine unsorted fraction, any material <40mm) \\
\hline 11 & Glass (packaging) & 25 & $\begin{array}{l}\text { Domestic hazardous waste (DHW), including batteries, car } \\
\text { batteries, etc. }\end{array}$ \\
\hline 12 & Inert wastes (stones, ceramics, concrete) & 26 & DHW (waste electrical and electronic equipment - WEEE) \\
\hline 13 & $\begin{array}{l}\text { Soft plastic (household articles, non-packing } \\
\text { films) }\end{array}$ & 27 & $\begin{array}{l}\text { DHW (household chemicals and household chemical } \\
\text { packaging, other hazardous waste) }\end{array}$ \\
\hline 14 & $\begin{array}{l}\text { Soft Plastic Packaging (Packaging, Disposable } \\
\text { Tableware) }\end{array}$ & & \\
\hline
\end{tabular}

To improve the detail of the obtained results and determine the share of specific waste components in the overall unsorted municipal waste stream, several separate waste fractions were 
added to the basic breakdown. For example, all waste components used in the packaging industry (plastic, paper, metal, etc.) were recorded as a separate fraction. In addition, a separate accounting of beverage carton packaging and other composite material packaging materials (like coffee and chips packaging, etc.) was carried out. Plastic bags were also recorded as a separate category. And three separate fractions of domestic hazardous waste were identified: electric accumulators and batteries, waste electrical and electronic equipment (WEEE) and household chemicals. These additional categories are mainly added to provide an opportunity for further research to assess efficiency of the extended producer responsibility schemes (directed specifically at packaging waste) and the efficiency of source sorting system simultaneously to the main aim of the study.

\subsection{Sorting Procedure}

The waste loads collected on the selected waste collection routes were delivered to waste management company sites for morphological composition analysis. After unloading, the sample was taken using a front loader; the test sample was at least $1 \mathrm{~m}^{3}$ or $250 \mathrm{~kg}$. The sample was weighed and delivered to the sorting site. A manual sample sorting by specified fractions was used, without applying any mechanical sorting equipment, mechanical treatment or grinding of test sample. Opening of waste bags was done manually. All separated waste fractions except for the "Fine matter" fraction were collected in separate and appropriately labelled waste containers. Sorting was performed until only the "Fine matter" fraction (fine particles with a size less than $40 \mathrm{~mm}$ ) remained on the floor. After sorting, all the separated fractions, including the "Fine matter" fraction, were weighed and the weighing results were recorded in the protocol. The protocol also recorded the date of the test, the responsible personnel, the origin of the sample - the place and source, the date of sampling, the total mass of the collection load, the mass of the sample prepared for sorting, and special notes or deviations, if any.

\subsection{Data Preparation and Analysis}

Data preparation and initial analysis was performed using MS Excel software, e.g., the share of each fraction in the total sample was calculated from the measured weights, while for further statistical data analysis of the interrelationships between waste composition and socio-economic factors both MS Excel and Statgraf software were used. Based on the method applied in [26], a correlation matrix between waste generation rate and percentages of individual waste fractions to identify whether a relationship exists between the variables. Our analysis indicated increased skew and kurtosis, for most data subsets, in which case log transformation is also typically suggested for data normalization [26]. As well, Edjabou et al. [26] emphasize that waste composition fraction data are a case of closed dataset, which requires special treatment, e.g. log transformation, prior to statistical analyses.

\section{RESUltS AND DISCUSSION}

Within the framework of the study, 160 samples of unsorted municipal waste were collected and sorted -5 samples from each of the 32 cities included in the study. The results characterize the composition of unsorted municipal waste and make it possible to assess the composition of unsorted waste as collected by the existing waste management system before pre-treatment and thus to evaluate the efficiency of that system. As well, it allows to assess which of the waste components (and their volumes) that are subject to source separation system are actually introduced to the unsorted waste stream, thus the analysis allows to prioritize the future incentives regarding improvement of the source separation system. At the same time, it should be taken into account that the composition and volume of source separated waste was not evaluated in the study. 
When interpreting the results, it was considered that the mass of the waste is defined for naturally wet waste, so, the moisture absorption capacity of different types of waste fractions impacts the results and the determined results should not be directly attributable to the dry composition of the waste. Edjabou et al. [26] also note that waste composition fractions that are calculated based on wet mass data enable the comparison between waste composition data of various cities and waste management regions and this approach also removes the impact of different waste generation rates. According to the applied method the Fines fraction was accounted as a separate fraction, but at the interpretation of the results the fines fraction was attributed in equal parts to biodegradable waste and inert materials.

The initial statistical analysis of the unsorted municipal waste variable (city average data) indicated a significant deviation from normal distribution, i.e. a positive skew and skinnier - thannormal kurtosis (standard skewness 12.3, standard kurtosis 33.8). This must be explained by the non-normal distribution of inhabitants in Latvian cities $-51.6 \%$ of national inhabitants live in the capital city Riga or the near Riga region [31]. In order to increase the normality of the dependent variable for the statistical analysis, a $\log$ arithm transformation $(\log (x))$ was selected as suggested by [33] and also applied to MSW by [33]. Following the transformation, a significant improvement was achieved for data skewness and kurtosis (standard skewness -0.03 , standard kurtosis -0.3 ). Similar normality problem was identified and fixed for the variable "Number of inhabitants".

TABLE 3. INDEPENDENT VARIABLES FOR REGRESSION ANALYSIS

\begin{tabular}{llll}
\hline & $\begin{array}{l}\text { Share of working } \\
\text { age inhabitants }\end{array}$ & $\begin{array}{l}\text { Average wage of } \\
\text { workers, EUR }\end{array}$ & $\log$ (Inhabitants) \\
\hline Count & 32 & 32 & 32 \\
Average & 0.63 & 784.84 & 8.91 \\
Standard deviation & 0.017 & 130.83 & 1.71 \\
Coeff. of variation & $2.68 \%$ & $16.67 \%$ & $19.13 \%$ \\
Minimum & 0.599 & 588.00 & 6.23 \\
Maximum & 0.666 & 1124.00 & 13.37 \\
Range & 0.066 & 536.00 & 7.14 \\
Stnd. skewness & -1.10 & 1.09 & 0.76 \\
Stnd. kurtosis & -0.55 & -0.06 & -0.001 \\
\hline
\end{tabular}

$\log ($ unsorted municipal waste $)=-4.20+1.28 \cdot \log ($ inhabitant $)$.

After the normalization of the variables, the mathematical model was developed by using city averaged data. As the literature analysis indicated that the waste amount is significantly related to social and behavioural factors, first a relation is sought between unsorted waste amounts, number of inhabitants, share of working age inhabitants and average wage in the city (Table 3). The developed model has $r^{2}$ of $95.94 \%$ (adjusted $r^{2}$ of $95.80 \%$ ) and takes into account only one of three proposed independent variables - number of inhabitants (Eq. (1)). Since the $p$-value of the model is 0.0000 , it is statistically significant at $95.0 \%$ confidence level. 


\subsection{Results of Unsorted Municipal Waste Composition}

The overall results indicate a quite significant dispersion of individual measurements of waste composition. This can be explained by the non-homogeneous nature of unsorted municipal waste, as well by the difference in consumer habits. When considering each city's average value out of five individual measurements, the dispersion of minimal and maximal values is more evened out (see Table 4).

With an average share of $29.2 \%$ (weight per cent), the largest share in the total waste stream is of biodegradable waste. The actual proportion of biodegradable waste is even higher, because it also constitutes up to $50 \%$ of the Fines fraction, so the total share of biodegradable waste (excluding paper, cardboard, wood, etc., which is biodegradable but included in other categories) could reach $38.83 \%$. Similar results for food waste, i.e., 41-45\%, are reported by Edjabou et al. [26], who identified food wastes as the dominating waste fraction in Danish household waste. Recyclable materials (including packaging), i.e., paper, cardboard, plastic, glass, constitute 32.23 $\%$ of total waste. With $12.02 \%$, the plastic waste constitutes the largest share in the group of materials suitable for recycling, followed by glass $(9.14 \%)$, paper/cardboard (8.09\%), and metals $2.98 \%$.

Although for many variables the standard skewness and kurtosis is higher than 2, overall the mean and median values are quite similar, thus indicating that there are no extreme outliers in each fraction's dataset. For some of the variables standard deviations are significant, also the coefficients of variation are high. The potential reason is the heterogeneity of waste composition; however, this ambiguity could be reduced in further studies by performing more sorting repetitions for each city. High standard deviations and coefficients of variation have also been reported for empirical waste composition analysis by [26].

TABle 4. Shares of Various Fractions of Unsorted Municipal Waste in LatVian Cities

\begin{tabular}{lllllllll}
\hline Waste fraction & Mean & $\begin{array}{l}\text { Standard } \\
\text { deviation }\end{array}$ & $\begin{array}{l}\text { Coeff. of } \\
\text { variation, } \\
\text { \% }\end{array}$ & Median & Min & Max & $\begin{array}{l}\text { Stnd. } \\
\text { skewness }\end{array}$ & $\begin{array}{l}\text { Stnd. } \\
\text { kurtosis }\end{array}$ \\
\hline $\begin{array}{l}\text { Biodegradable } \\
\text { waste }\end{array}$ & 29.22 & 5.39 & 18.43 & 28.96 & 14.14 & 37.47 & -1.48 & 0.29 \\
$\begin{array}{l}\text { Paper, cardboard } \\
\text { Paper, cardboard }\end{array}$ & 4.65 & 1.47 & 31.63 & 4.72 & 1.99 & 7.87 & 0.43 & -0.17 \\
(packaging) & 1.44 & 33.90 & 3.38 & 1.88 & 6.32 & 2.58 & 1.42 \\
$\begin{array}{l}\text { Beverage } \\
\text { packaging }\end{array}$ & 1.37 & 0.52 & 38.23 & 1.26 & 0.76 & 2.97 & 3.52 & 2.74 \\
Wood & 0.56 & 0.45 & 78.30 & 0.46 & 0 & 1.74 & 3.15 & 1.60 \\
Wood & 0.16 & 0.22 & 142.66 & 0.08 & 0 & 1.01 & 5.29 & 7.16 \\
(packaging) & & & & & & & & \\
Hygienic wastes & 6.30 & 2.46 & 39.05 & 5.94 & 2.27 & 14.65 & 3.24 & 3.71 \\
Textiles & 5.04 & 1.37 & 27.18 & 4.71 & 2.50 & 8.96 & 2.37 & 1.93 \\
Leather, rubber & 0.76 & 0.62 & 81.78 & 0.62 & 0 & 1.82 & 1.06 & -1.42 \\
Glass & 1.14 & 0.63 & 55.43 & 1.03 & 0.31 & 3.05 & 2.75 & 1.73 \\
Glass (packaging) & 8.00 & 2.11 & 26.32 & 8.26 & 2.37 & 11.41 & -1.10 & 0.01 \\
Inert wastes & 2.08 & 2.01 & 96.52 & 1.28 & 0.30 & 10.11 & 5.25 & 8.23 \\
Soft plastics & 1.41 & 0.72 & 51.00 & 1.26 & 0.24 & 3.84 & 2.81 & 3.16 \\
\hline & & & & & & & & \\
\hline
\end{tabular}




\begin{tabular}{|c|c|c|c|c|c|c|c|c|}
\hline Waste fraction & Mean & $\begin{array}{l}\text { Standard } \\
\text { deviation }\end{array}$ & $\begin{array}{l}\text { Coeff. of } \\
\text { variation, } \\
\%\end{array}$ & Median & Min & Max & $\begin{array}{l}\text { Stnd. } \\
\text { skewness }\end{array}$ & $\begin{array}{l}\text { Stnd. } \\
\text { kurtosis }\end{array}$ \\
\hline $\begin{array}{l}\text { Soft plastics } \\
\text { (packaging) }\end{array}$ & 1.58 & 0.56 & 35.52 & 1.55 & 0.72 & 2.75 & 0.68 & -1.01 \\
\hline $\begin{array}{l}\text { Soft plastics } \\
\text { (bags) }\end{array}$ & 3.73 & 1.47 & 39.26 & 3.82 & 1.50 & 6.87 & 0.81 & -0.63 \\
\hline Dense plastics & 0.82 & 0.37 & 44.47 & 0.75 & 0.33 & 1.98 & 2.89 & 2.20 \\
\hline $\begin{array}{l}\text { Dense plastics } \\
\text { (packaging) }\end{array}$ & 4.48 & 3.20 & 71.44 & 3.16 & 1.65 & 12.93 & 3.96 & 1.70 \\
\hline Carpets & 0.48 & 0.37 & 76.03 & 0.53 & 0 & 1.24 & 0.65 & -1.08 \\
\hline Ferrous metal & 0.62 & 0.39 & 63.20 & 0.53 & 0.15 & 1.70 & 3.36 & 2.25 \\
\hline $\begin{array}{l}\text { Ferrous metal } \\
\text { (packaging) }\end{array}$ & 1.39 & 0.58 & 41.94 & 1.23 & 0.72 & 3.10 & 3.25 & 2.23 \\
\hline Non-ferrous metal & 0.21 & 0.29 & 139.00 & 0.10 & 0 & 1.14 & 4.30 & 3.40 \\
\hline $\begin{array}{l}\text { Non-ferrous metal } \\
\text { (Packaging) }\end{array}$ & 0.76 & 0.30 & 39.50 & 0.66 & 0.29 & 1.34 & 1.12 & -1.12 \\
\hline $\begin{array}{l}\text { Composite } \\
\text { material } \\
\text { packaging }\end{array}$ & 0.64 & 0.41 & 63.72 & 0.49 & 0.19 & 1.95 & 3.91 & 3.41 \\
\hline Fine matter & 19.23 & 3.30 & 17.18 & 19.51 & 12.70 & 25.81 & 0.13 & -0.75 \\
\hline $\begin{array}{l}\text { DHW (batteries, } \\
\text { accumulators) }\end{array}$ & 0.23 & 0.22 & 95.37 & 0.17 & 0.01 & 0.93 & 4.03 & 3.99 \\
\hline DHW (WEEE) & 0.54 & 0.45 & 84.30 & 0.37 & 0.08 & 2.08 & 4.16 & 4.06 \\
\hline $\begin{array}{l}\text { DHW (chemicals } \\
\text { etc.) }\end{array}$ & 1.16 & 0.52 & 44.83 & 0.97 & 0.59 & 2.70 & 3.26 & 1.77 \\
\hline
\end{tabular}

The applied methodology also allowed to separately analyse all packaging waste streams. The total share of all packaging in the unsorted waste stream was $25.55 \%$. Sorting results show that the largest proportion of packaging waste is made up of glass packaging $8.00 \%$, followed by plastic packaging $6.06 \%$, paper and cardboard packaging $3.44 \%$, metal packaging $2.15 \%$. Plastic bags were also sorted separately when determining the composition of the waste, and the results show that plastic bags account for $3.7 \%$ of the total waste. These results may be significant for the future discussions in relation to increasing the recovery rate for packaging waste.

The remaining waste groups account for $26.75 \%$, of which inert waste (including also $1 / 2$ of Fines fraction) was $11.67 \%$, domestic hazardous waste and environmentally harmful goods $1.93 \%$, miscellaneous materials, including textiles, rubber, wood, hygiene waste, etc., constituted about $13.15 \%$.

In addition to experimentally determined waste compositions, data on the total waste generation and inhabitants in Latvian cities was acquired from statistics. The data on the amounts of unsorted municipal waste in each of the cities was acquired from National Statistics database Waste-3, where for the nine largest cities the data was directly extracted from the database. For the smaller cities the total amount of waste generated in the city is calculated from county-level statistics by considering the number of inhabitants in each county and the city itself. Following the specific waste amount in tons per inhabitant was calculated. The data is further analysed by application of Spearman's correlation test similarly as done by [26]. To elaborate the analysis, and based on the previous conclusion that there is a strong relation between waste amount and number of inhabitants, an additional indicator - specific waste amount (SWA, t/inhabitant) - is developed by 
attributing unsorted waste amount to number of city inhabitants. The statistical analysis identifies standard skewedness and kurtosis for this indicator to be in range appropriate to a normal distribution data. Thus, use of this indicator also allows dealing with the previously discussed problems of non-normal distribution.

For this assessment the individual waste fractions are grouped based on waste components (as suggested by NT ENVIR 001 method), the potential management options (e.g., there is no dedicated waste incineration plants in Latvia, so the other combustible waste group was not distinguished separately), as well as some specific requirements - e.g. extended producer responsibility schemes for packaging waste or landfill ban for hazardous wastes. The acquired breakdown makes it possible to estimate the volumes of different waste streams and to compare the proportion of waste types by the city groups. The analysis considers the following groups:

1. Biodegradable waste - including the separate biodegradable waste fraction and half of the Fine matter fraction;

2. Paper - including paper, cardboard and packaging thereof;

3. Plastics - all plastics fractions including packaging, bags, soft and dense plastics;

4. Glass - including glass and glass packaging;

5. Metal - including ferrous and non-ferrous metals and packaging thereof;

6. Packaging - including all other packaging fractions as composite materials, beverage packaging, wood packaging;

7. Inert wastes - including the inert fraction and half of the Fine matter fraction;

8. Hazardous wastes - including all three groups of hazardous wastes;

9. Others - including the remaining fractions including, wood, hygiene waste, textile, leather, rubber, carpets.

The correlation test results (Table 5) indicate that there are some underlying relationships between the waste fraction variables. Especially strong and specifically significant correlations are identified between biodegradable wastes and plastics, between other wastes and hazardous wastes, paper, fines and biodegradable wastes. Weaker negative, but significant correlations are identified between share of working age population and the fraction of inert wastes, and between hazardous waste fraction share and average wage variable.

TABle 5. SPEARMAN RANK CORRELATIONS FOR WASTE COMPOSITION FRACTIONS

\begin{tabular}{|c|c|c|c|c|c|c|c|c|c|c|c|c|c|c|}
\hline & 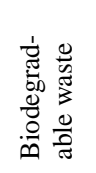 & $\begin{array}{l}\bar{\Xi} \\
\text { है } \\
\text { D. }\end{array}$ & 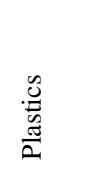 & $\begin{array}{l}\tilde{\tilde{\sigma}} \\
\frac{\tilde{\sigma}}{0}\end{array}$ & $\frac{\pi}{\stackrel{\pi}{0}}$ & 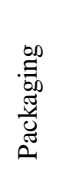 & $\stackrel{\Xi}{\Xi}$ & 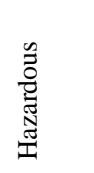 & $\frac{n}{\tilde{\omega}}$ & $\underset{\Xi}{\varrho}$ & $\frac{2}{3}$ & $\underset{\mathbb{I}}{3}$ & 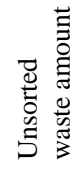 & 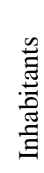 \\
\hline Paper & 0.23 & & & & & & & & & & & & & \\
\hline Plastics & $-0.68^{* *}$ & $-0.51^{* *}$ & & & & & & & & & & & & \\
\hline Glass & $-0.45^{*}$ & -0.02 & 0.24 & & & & & & & & & & & \\
\hline Metal & $-0.50^{* *}$ & -0.10 & 0.28 & 0.32 & & & & & & & & & & \\
\hline Packaging & -0.24 & $0.36^{*}$ & -0.18 & 0.10 & 0.19 & & & & & & & & & \\
\hline Inert & $-0.55^{* *}$ & -0.18 & $0.60^{* *}$ & 0.15 & 0.29 & -0.32 & & & & & & & & \\
\hline Hazardous & $-0.56^{* *}$ & $-0.40^{*}$ & $0.35^{*}$ & 0.06 & $0.55^{* *}$ & -0.00 & 0.28 & & & & & & & \\
\hline Others & $-0.69^{* *}$ & $-0.64^{* *}$ & $0.52^{* * *}$ & 0.21 & $0.54^{* *}$ & -0.09 & 0.30 & $0.72^{* *}$ & & & & & & \\
\hline Fines & $0.36^{*}$ & 0.35 & $-0.36^{*}$ & $-0.36^{*}$ & $-0.60^{* *}$ & 0.19 & -0.24 & $-0.42^{*}$ & $-0.67^{* *}$ & & & & & \\
\hline WAP & 0.09 & 0.22 & -0.35 & -0.12 & -0.02 & 0.34 & $-0.52^{* *}$ & -0.01 & -0.09 & 0.09 & & & & \\
\hline
\end{tabular}




\begin{tabular}{lllllllllllllll}
\hline EAW & 0.07 & 0.11 & 0.05 & -0.20 & -0.24 & 0.12 & -0.01 & $-0.36^{*}$ & -0.17 & 0.12 & 0.01 & & & \\
Unsorted & 0.17 & 0.33 & -0.33 & -0.13 & -0.16 & $0.37^{*}$ & -0.26 & -0.14 & -0.34 & 0.30 & 0.19 & 0.34 & \\
MSW & & & & & & & & & & & & & \\
Inhabitants & 0.20 & 0.33 & -0.34 & -0.19 & -0.21 & 0.33 & -0.26 & -0.19 & $-0.38^{*}$ & 0.34 & 0.16 & $0.35^{*}$ & $0.99^{* *}$ \\
SWA & 0.10 & 0.16 & -0.24 & 0.01 & -0.07 & 0.32 & -0.26 & -0.04 & -0.21 & 0.13 & 0.26 & 0.26 & $0.86^{* *}$ & $0.81^{* *}$ \\
\hline
\end{tabular}

"Medium significance probability between 0.01 and $0.05,{ }^{* * *}$ High significance probability between 0.001 and 0.01 ; WAP - Share of working age population, \%; EAW - Employee average wages, euro; SWA - Specific waste amount, t/inhabitant.

Interestingly only packaging waste fraction correlated significantly with unsorted waste amount; however, no significant correlations are identified between SWA and the particular waste fractions, which could be due to the reason that SWA is based on statistical data and were not measured. Thus, this means that as determined before, the amount of unsorted waste generation is strongly related to the number of inhabitants, however waste composition is affected by other factors than specific waste generation amount.

\subsection{Results of Unsorted Municipal Waste Composition Analysed by City Groups}

To further investigate the obtained data and to find hidden patterns that characterize the existing waste management system, we analyse waste composition by city groups (accordingly to classification in Table 1). First the average specific amount of unsorted municipal waste was calculated for each city group based on data provided by statistics. The average specific amount of unsorted municipal waste for all dataset was $207 \mathrm{~kg} /$ per inhabitant. Fig. 1(a) presents the results on specific unsorted municipal waste amounts for five city groups classified by the number of inhabitants. The results indicate a higher specific waste amount in the largest cities, while in the smallest cities the specific waste amount is even half of the average. To investigate the reasons for this tendency, waste composition differences will be further analysed. Meanwhile, Fig. 1(b) characterizes this tendency by applying linear regression. The $r^{2}$ of this relationship is 0.505 , however the data for Riga (capital city) was excluded from this dataset due to its significantly larger number of inhabitants, which thus produces significant skew and reduces the correlation coefficient. Though this relation is only of average strength, this indicates that there is a difference between waste generation behaviour due to different city sizes.

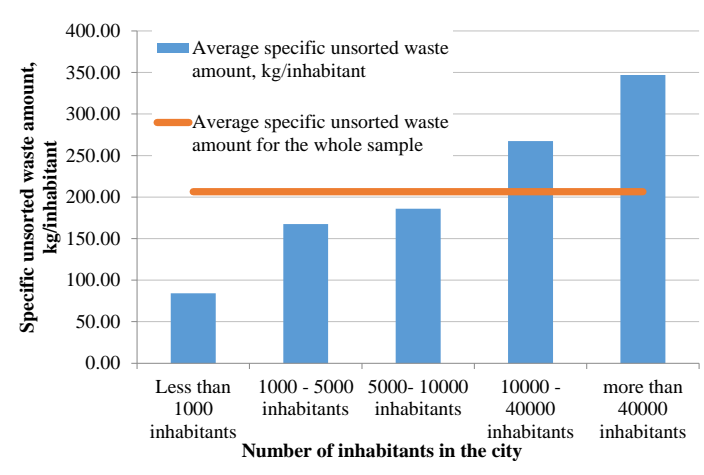

a)

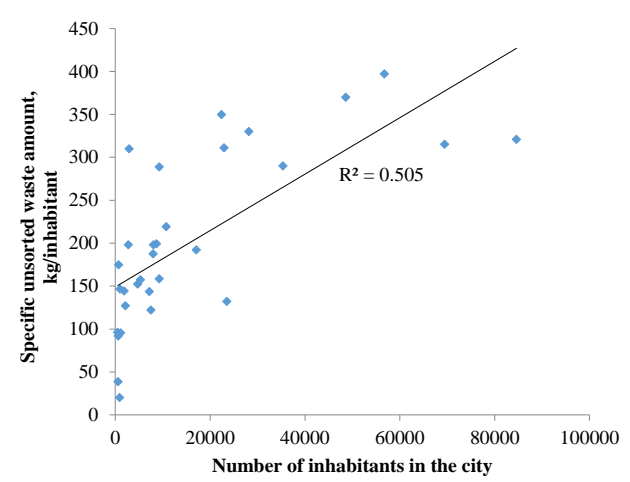

b)

Fig. 1. Specific amount of unsorted municipal waste in the analysed cities.

(Note: Riga is excluded from dataset in the Fig. 1(b), due to its significantly larger number of inhabitants) 
The results of the determination of the composition of unsorted municipal waste by groups of cities are graphically presented in Fig. 2. The biodegradable waste group constitutes the largest share of the total waste stream in all city samples. The largest proportion of biodegradable waste is found in cities with a population of 10 to 40 thousand inhabitants, while the lowest proportion in cities with a population of 1-5 thousand inhabitants. No direct correlation between the proportion of biodegradable waste and population groups is identified. The high share of biodegradable waste in all samples indicates the need to address the issue of biodegradable waste recycling.

The difference between minima and maxima share for paper waste for the considered city groups is $1.8 \%$, with the highest share being for the largest cities. For paper wastes a direct relation is evident as the share of paper wastes in the total amount of waste increases with increasing number of city inhabitants. Overall, the paper waste ratio is characterized as relatively low (compared to previous empirical experience in Latvia). However, especially for paper waste, mixing with unsorted waste stream can significantly damage the quality of paper and therefore is may not be separable and usable. Similar to paper waste, for plastic waste the results indicate more significant relation regarding city size groups, only in this case, larger share is identified for smaller towns. In general, the proportion of metal waste is considered high, to some extent it can be seen as an opportunity to increase the amount of waste recycling, because metal waste is relatively easy to separate from unsorted waste stream and, at the same time, metal waste has existing realization possibilities.

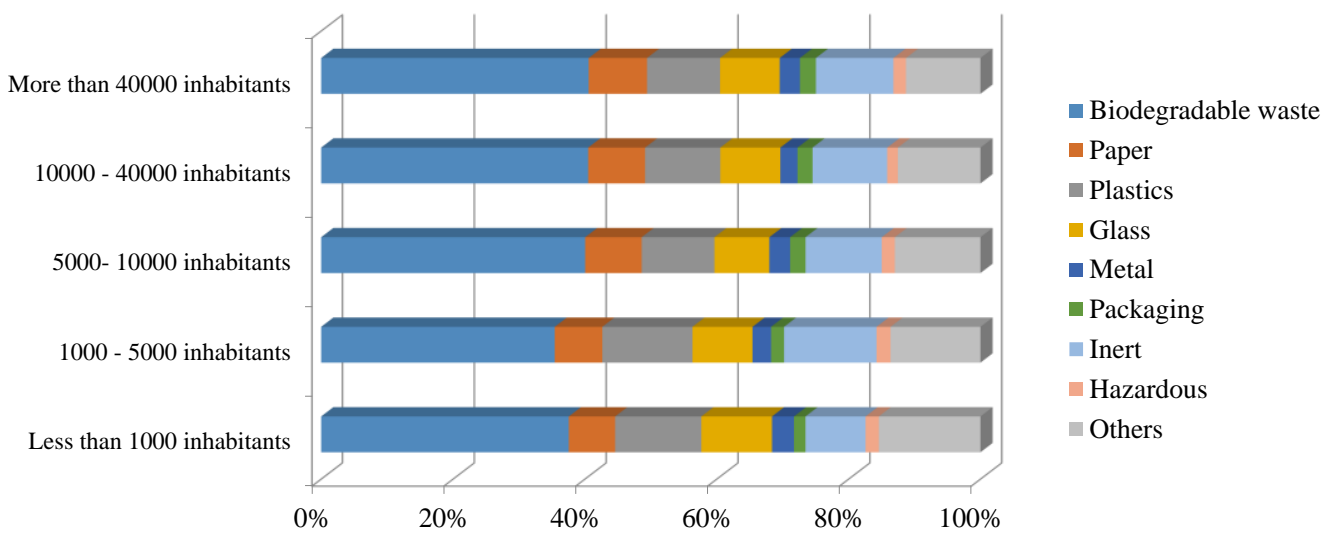

Fig. 2. Results of waste composition by city groups.

When analysing the proportion of inert waste, it is concluded that it varies significantly between in different city groups, which could be explained by the casual nature of these wastes. The share of hazardous waste is considered high, which points to the need to address the issue of extending the possibilities for source separation of hazardous waste. The share of other wastes, including, wood, textiles, rubber, hygiene waste, etc. is higher for the smaller cities and is decreasing with the increasing number of city inhabitants. It should be noted that in this group about $2 / 3$ of the total volume of the group is made up of textile waste and hygiene waste, while the rest - wood, rubber, leather - no more than $1 / 3$ of the group size. 


\subsection{Results of Unsorted Municipal Waste Composition Analysed by Waste Management Regions}

In addition to analysing the gathered data regarding city size, we are able to analyse them by affiliation to different waste management regions (Fig. 2). According to the National waste management plan, the territory of Latvia is divided into 10 waste management regions, each of which has a designated sanitary landfill. The waste management business models are quite different in these regions; some municipalities have cooperated to establish a municipal waste collection and management company, in other regions municipalities choose a single private company that the inhabitants are required to contract, while the territory of the capital city Riga is divided between several private companies, thus ensuring higher market competition. For nine of regions data on at least two different cities were available, however for one of the regions only one city data was available. Nevertheless, it is interesting to analyse if waste composition data allows to identify some differences between these regions.

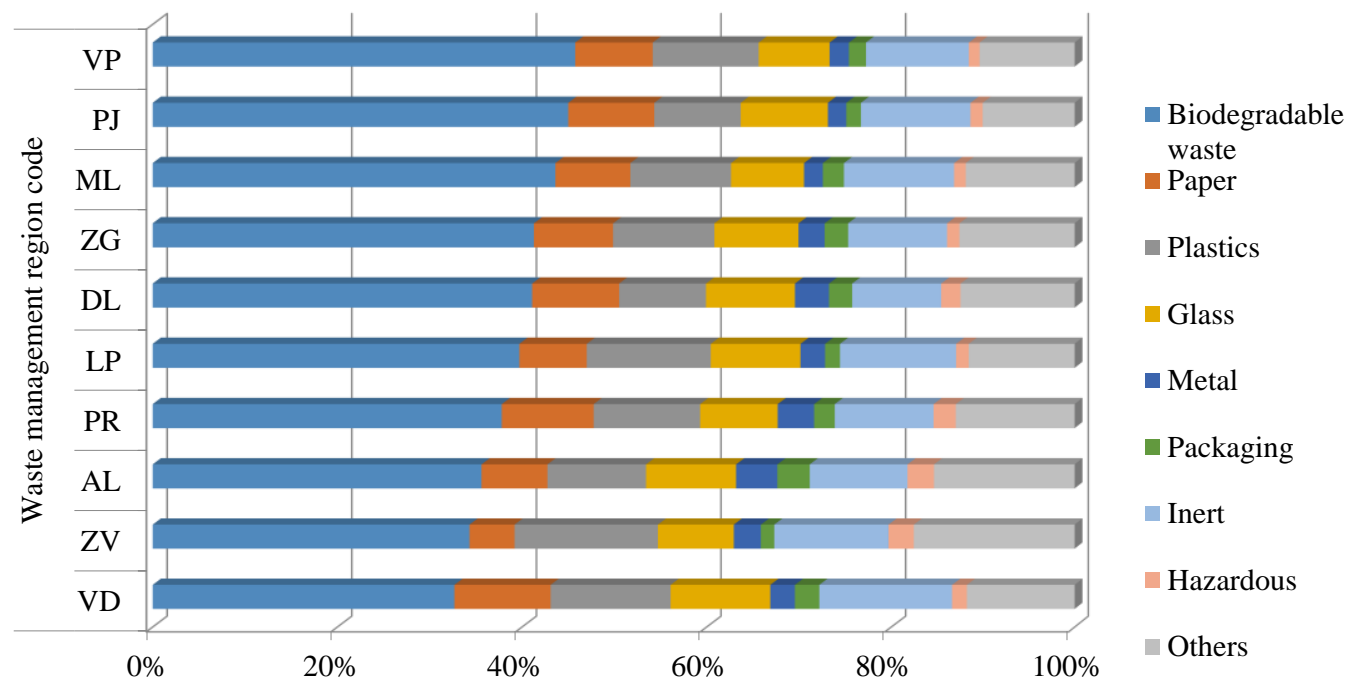

Fig. 3. Results of waste composition by waste management regions. (Note: only one city data was assessed for the ML region).

The overall results indicate that the share of recyclables (glass, paper, plastics, metal) in different waste management regions average at $32 \%$ of unsorted municipal waste. Of the separate fractions of recyclable waste, the highest difference between the regions is for plastic waste. The overall largest difference between the minimal and maximal values in different regions is for the biodegradable waste fraction with minima being $32.68 \%$ and maxima $-45.77 \%$. However, the biodegradable waste fraction is often most sensitive to case specific circumstances. The other largest waste fractions - Others and Inert wastes - constitute around 12.69 and $11.59 \%$ of the total waste accordingly. However more in-depth research on consumer habits would be needed for further conclusions regarding waste management region comparison.

The regionally classified dataset is significantly skewed, and even with normalization technique applied, it was not possible to develop a statistically significant mathematical model from the currently available data to mathematically characterize the differences between waste management regions. 


\section{Conclusions}

The presented research is the first step towards the development of integrated waste management system for Latvia that also corresponds to circular economy concepts. The literature analysis indicates that data gathering and analysis regarding the amounts and composition of waste flows are substantial input data for the development of circular and integrated waste management system. Therefore, the empirical data gathering allows for the initial analysis of the existing waste management system. The existing waste management system in Latvia has been developed mainly in order to comply with common EU waste management requirements. But, in order to move towards higher level of material circulation in our economy, the resource recovery rates should be significantly improved, first by increasing the recovery of recyclable or compostable materials. The experimental results indicate that the unsorted municipal waste stream comprises of up to $32.9 \%$ of recyclable materials and $29.2 \%$ of biodegradable wastes. Thus almost $60 \%$ of the waste currently being subjected to the unsorted waste management system in Latvia could potentially be source separated ensuring higher quality of the recovered materials and promoting the development of circular economy value chains. In addition, some grassroots movements are locally available for collection of textile wastes; the mainstreaming of these initiatives could additionally divert waste from landfills.

The results allow characterization of the existing waste management system, particularly the waste composition by different waste management regions and by different groups of cities that are classified by their inhabitant size. The results regarding different city size groups indicate a clear relation between the number of city inhabitants and specific waste generation amounts. The reasons for this tendency may be further studied by in-depth investigation of waste producer habits.

The results indicate slight differences between waste composition in different waste management regions, thus noting that, in addition to the number of inhabitants and their habits, the local system in each waste management region may influence the composition of the collected wastes, particularly important is the existing source separation system. However, the gathered data did not allow to develop a mathematical model to differentiate between the various waste management regions, and further research can be extended in this direction.

The conclusions allow focussing future investigations regarding inhabitant waste generation habits towards a smaller set of indicative variables, thus saving resources and time consumption for the study. Makarichi et al. [33] emphasize that evaluation of the existing waste management system leads to the next problem - a decision-making problem related to selection of the future development options. While this investigation is crucial for assessment of the existing waste management system, it is also necessary to further analyse the development possibilities for waste management system in Latvia, especially by assessing the potential for the development of circular integrated waste management system and circular value chains. The obtained results may be further used in such study as a reference or as input information for population selection for a larger-scale study.

\section{ACKNOWLEDGEMENT}

This research is funded by the Ministry of Economics of the Republic of Latvia, project "Sustainable and renewable transport policy formulation in Latvia (4muLATe)", project No. VPP-EM-2018/AER_2_0003. 


\section{REFERENCES}

[1] Mohammadi M., Jämsä-Jounela S. L., Harjunkoski I. Optimal planning of municipal solid waste management systems in an integrated supply chain network. Computers \& Chemical Engineering 2019:123:155-169. doi:10.1016/j.compchemeng.2018.12.022

[2] Barisa A., Dzene I., Rosa M., Dobraja K. Waste-to-biomethane Concept Application: A Case Study of Valmiera City in Latvia. Environmental and Climate Technologies 2015:15:48-58. doi:10.1515/rtuect-2015-0005

[3] Dzene I., et al. Energy Recovery from End-of-Life Tyres: Untapped Possibility to Reduce $\mathrm{CO}_{2}$ Emissions. Environmental and Climate Technologies 2010:4(1):35-41. doi:10.2478/v10145-010-0015-6

[4] Priedniece V., et al. Bioproducts from Potatoes. A Review. Environmental and Climate Technologies 2017:21(1):18-27. doi:10.1515/rtuect-2017-0013

[5] Spalvins K., Blumberga D. Production of Fish Feed and Fish Oil from Waste Biomass Using Microorganisms: Overview of Methods Analyzing Resource Availability. Environmental and Climate Technologies 2018:22(1):149-164. doi:10.2478/rtuect-2018-0010

[6] Cobo S., Dominguez-Ramos A., Irabien A. From linear to circular integrated waste management systems: A review of methodological approaches. Resources, Conservation and Recycling 2018:135:279-295. doi:10.1016/j.resconrec.2017.08.003

[7] Lieder M., Rashid A. Towards circular economy implementation: a comprehensive review in context of manufacturing industry. Journal of Cleaner Production 2016:115:36-51. doi:10.1016/j.jclepro.2015.12.042

[8] Reike D., Vermeulen W. J. V., Witjes S. The circular economy: New or Refurbished as CE 3.0? - Exploring Controversies in the Conceptualization of the Circular Economy through a Focus on History and Resource Value Retention Options. Resources, Conservation and Recycling 2018:135:246-264. doi:10.1016/j.resconrec.2017.08.027

[9] Velenturf A. P. M., Jopson J. S. Making the business case for resource recovery. Science of The Total Environment 2019:648:1031-1041. doi:10.1016/j.scitotenv.2018.08.224

[10] Eurostat Database. Generation of waste by waste category, hazardousness and NACE Rev. 2 activity.

[11] Central Bureau of Statistics 2019. Environment and Energy database, VIG040. Municipal and hazardous waste: collection and treatment.

[12] Castillo-Giménez J., Montañés A., Picazo-Tadeo A. J. Performance and convergence in municipal waste treatment in the European Union. Waste Management 2019:85:222-231. doi:10.1016/j.wasman.2018.12.025

[13] Eurostat Database. Treatment of waste by waste category, hazardousness and waste management operations.

[14] Ministry of Environmental Protection and Regional Development of Latvia, 2013. National Waste Management Plan 2013-2020 [Online]. [Accessed 11.04.2019]. Available: http://polsis.mk.gov.lv/api/file/file9833.doc

[15] Rosa M., Beloborodko A. A decision support method for development of industrial synergies: case studies of Latvian brewery and wood-processing industries. Journal of Cleaner Production 2015:105:461-470. doi:10.1016/j.jclepro.2014.09.061

[16] Dahlén L., Lagerkvist A. Methods for household waste composition studies. Waste Management 2008:28(7):1100-1112. doi:10.1016/j.wasman.2007.08.014

[17] Bisinella V., et al. Importance of waste composition for Life Cycle Assessment of waste management solutions. Journal of Cleaner Production 2017:164:1180-1191. doi:10.1016/j.jclepro.2017.07.013

[18] Arena U., Di Gregorio F. A waste management planning based on substance flow analysis. Resources, Conservation and Recycling 2014:85:54-66. doi:10.1016/j.resconrec.2013.05.008

[19] Keser S., Duzgun S., Aksoy A. Application of spatial and non-spatial data analysis in determination of the factors that impact municipal solid waste generation rates in Turkey. Waste Management 2012:32:359-371. doi:10.1016/j.wasman.2011.10.017

[20] Kumar A., Samadder S. R. An empirical model for prediction of household solid waste generation rate - A case study of Dhanbad, India. Waste Management 2017:68:3-15. doi:10.1016/j.wasman.2017.07.034

[21] Vu H. L., et al. Time-lagged effects of weekly climatic and socio-economic factors on ANN municipal yard waste prediction models. Waste Management 2019:84:129-140. doi:10.1016/j.wasman.2018.11.038

[22] Oribe-Garcia I., et al. Identification of influencing municipal characteristics regarding household waste generation and their forecasting ability in Biscay. Waste Management 2015:39:26-34. doi:10.1016/j.wasman.2015.02.017

[23] Kolekar K. A., Hazra T., Chakrabarty S. N. A Review on Prediction of Municipal Solid Waste Generation Models. Procedia Environmental Sciences 2016:35:238-244. doi:10.1016/j.proenv.2016.07.087

[24] Lebersorger S., Schneider F. Discussion on the methodology for determining food waste in household waste composition studies. Waste Management 2011:31(9-10):1924-1933. doi:10.1016/j.wasman.2011.05.023

[25] Latvian Environment Geology and Meteorology Center. Summary of the National Statistical Report No.3 - Waste Overview of Waste for 2017. Riga: LVGMC, 2018.

[26] Jorissen J., Priefer C., Bräutigam K. R. Food waste generation at household level: results of a survey among employees of two European research centers in Italy and Germany. Sustainability 2015:7(3):2695-2715. doi:10.3390/su7032695

[27] Elimelech E., Ayalon O., Ert E. What gets measured gets managed: A new method of measuring household food waste. Waste Management 2018:76:68-81. doi:10.1016/j.wasman.2018.03.031 
[28] Nordtest, 1995. Municipal Solid Waste: Sampling and Characterisation (No. NT ENVIR 001), Nordtest Method. Espoo, Finland [Online]. [Accessed 14.02.2019.]. Available: http://www.nordtest.info/index.php/methods/item/solidwaste-municipal-sampling-and-characterisation-nt-envir-001.html

[29] SWA-Tool Consortium, 2004. Methodology for the Analysis of Solid Waste (SWA-Tool). User Version [Online]. [Accessed 14.02.2019.]. Available: https://www.wien.gv.at/meu/fdb/pdf/swa-tool-759-ma48.pdf

[30] European Committee for Standardization. CEN-CENELEC Management Centre Brussels, Belgium.

[31] LVS EN 15440:2011. Solid recovered fuels - Methods for the determination of biomass content.

[32] Edjabou M. E., et al. Municipal solid waste composition: Sampling methodology, statistical analyses, and case study evaluation. Waste Management 2015:36:12-23. doi:10.1016/j.wasman.2014.11.009

[33] Abbott D. Applied Predictive Analytics: Principles and Techniques for the Professional Data Analyst. John Wiley \& Sons, Incorporated, 2014.

[34] Central Bureau of Statistics. Population database. Annual data [Accessed 14.02.2019.]. Available: https://data1.csb.gov.lv/pxweb/en/iedz/iedz_iedzskaits_ikgad/ISG020.px/?rxid=5afa4e1e-94bf-4758-9c96315f3e9943a9

[35] Lebersorger S., Beigl P. Municipal solid waste generation in municipalities: Quantifying impacts of household structure, commercial waste and domestic fuel. Waste Management 2011:31:9-10. doi:10.1016/j.wasman.2011.05.016

[36] Makarichi L., Techato K., Jutidamrongphan W. Material flow analysis as a support tool for multi-criteria analysis in solid waste management decision-making. Resources, Conservation and Recycling 2018:139:351-365. doi:10.1016/j.resconrec.2018.07.024 